Goldschmidt 2021 Abstract

https://doi.org/10.7185/gold2021.5243

\section{Remobilization of Uranium from a Bioreduced Field Sediment by Organic Ligands}

\author{
KYLE J CHARDI ${ }^{1}$, MARIO ALVAREZ SALAS ${ }^{2}$, NARESH \\ KUMAR $^{1}$, WALTER D.C. SCHENKEVELD ${ }^{3}$, VINCENT \\ NOEL $^{4}$, PETRA PJEVAC ${ }^{1,5}$, DANIEL GIAMMAR ${ }^{6}$ AND \\ STEPHAN M. KRAEMER ${ }^{1}$ \\ ${ }^{1}$ University of Vienna \\ ${ }^{2}$ Department of Environmental Systems Science, ETH Zürich \\ ${ }^{3}$ Wageningen University \& Research \\ ${ }^{4}$ SLAC National Accelerator Laboratory \\ ${ }^{5}$ Joint Microbiome Facility of the Medical University of Vienna \\ and the University of Vienna \\ ${ }^{6}$ Washington University in St. Louis \\ Presenting Author: kyle.chardi@univie.ac.at
}

Uranium (U) bioreduction is a strategy often utilized in remediation efforts where an electron donor is added to neighbouring injection wells to facilitate the reduction of soluble $\mathrm{U}(\mathrm{VI})$ to sparingly soluble $\mathrm{U}(\mathrm{IV})$. Yet, it is becoming increasingly evident that reduced forms of U(IV) are more labile than previously assumed and that these U(IV) minerals and phases are susceptible to releasing appreciable amounts of $U$ into drinking water even in the absence of any oxidants.

In order to gain insights into how organic ligands present in the environment could factor into remediation efforts and the stability of U(IV) under reducing conditions, a series of experiments were conducted with bioreduced field sediments from Retz, Austria to assess the mobilization of $U$ in such sediments by a variety of structurally diverse organic ligands (low-molecular-weight organic acids, synthetic chelators). Anoxic flow-through column experiments were conducted to stimulate biologically-mediated reduction of soluble $U$ in the presence of an electron donor (glucose) and an artificial groundwater (AGW) solution to mimic field conditions. After sufficient reduction and accumulation of $U$ within the column, the mobility of $U$ was probed with the aforementioned ligands. Aqueous samples were collected from the column effluent for measurement of soluble $U$ concentrations as well as other redox reactive elements $(\mathrm{Fe}, \mathrm{Mn})$ and species $\left(\mathrm{S}^{2-}\right)$.

These studies were complemented by batch mobilization experiments, sorption studies, as well as a multi-faceted approach to characterize the bioreduced sediment including Xray absorption spectroscopy, sequential chemical extraction, and 16S rRNA gene-based microbial community profiling. Additionally, geochemical transport modelling was applied to further draw mechanistic insights.

While reduced $U$ in flow-through columns was found to be in a labile-bound form, both batch and column experiments confirmed that in control treatments (AGW), U concentrations remained extremely low. Yet, in organic ligand treatments, $U$ concentrations increased considerably. The findings of this work underpin the lability of U(IV) even under reducing conditions in anoxic environments, such as seen in bioremediation practices at subsurface contaminated sites. These results have implications for the efficacy of remediation efforts to meet and maintain drinking water standards in both Retz and other field sites with like-conditions. 